\title{
The ciliary proteins Meckelin and Jouberin are required for retinoic acid-dependent neural differentiation of mouse embryonic stem cells
}

\author{
S Romani ${ }^{1 *}$, B $\mid l i^{2}$, R De Mori ${ }^{1}, J G$ Gleeson ${ }^{3}$, EM Valente ${ }^{4}$ \\ From First International Cilia in Development and Disease Scientific Conference (2012) \\ London, UK. 16-18 May 2012
}

The dysfunction of the primary cilium, a complex, evolutionarily conserved, organelle playing an important role in sensing and transducing cell signals, is the unifying pathogenetic mechanism of a growing number of diseases collectively termed "ciliopathies", typically characterized by multiorgan involvement. Developmental defects of the central nervous system (CNS) characterize a subset of ciliopathies showing clinical and genetic overlap, such as Joubert syndrome (JS) and Meckel Syndrome (MS). Although several knock-out mice lacking a variety of ciliary proteins have shown the importance of primary cilia in the development of the brain and CNS-derived structures, developmental in vitro studies, extremely useful to unravel the role of primary cilia along the course of neural differentiation, are still missing. Mouse embryonic stem cells (mESCs) have been recently proven to mimic brain development, giving the unique opportunity to dissect the CNS differentiation process along its sequential steps. In the present study we show that mESCs express the ciliary proteins Meckelin and Jouberin in a developmentally-regulated manner, and that these proteins co-localize with acetylated tubulinlabeled cilia located at the outer embryonic layer. Further, mESCs differentiating along the neuronal lineage activate the cilia-dependent sonic hedgehog signaling machinery, which seems to be impaired in Meckelin knock-down cells but results unaffected in Jouberindeficient mESCs. However, both seems to lose the ability to acquire a neuronal phenotype. Altogether these findings suggest a pivotal role of Meckelin and Jouberin during embryonic neural specification and indicate mESCs as a suitable tool to investigate the developmental impact of ciliary proteins dysfunction.

\footnotetext{
*Correspondence: s.romani@css-mendel.it

${ }^{1}$ Istituto Casa Sollievo della Sofferenza- Mendel Laboratory, Italy

Full list of author information is available at the end of the article
}

\section{Author details}

${ }^{1}$ Istituto Casa Sollievo della Sofferenza- Mendel Laboratory, Italy. ${ }^{2}$ Consiglio Nazionale delle Ricerche (CNR), Italy. ${ }^{3}$ Howard Hughes Medical Institute, University of California, USA. ${ }^{4}$ University of Messina, Department of Medical and Surgical Pediatric, Italy.

Published: 16 November 2012

doi:10.1186/2046-2530-1-S1-P77

Cite this article as: Romani et al:: The ciliary proteins Meckelin and

Jouberin are required for retinoic acid-dependent neural differentiation of mouse embryonic stem cells. Cilia 2012 1(Suppl 1):P77.

Submit your next manuscript to BioMed Central and take full advantage of:

- Convenient online submission

- Thorough peer review

- No space constraints or color figure charges

- Immediate publication on acceptance

- Inclusion in PubMed, CAS, Scopus and Google Scholar

- Research which is freely available for redistribution 